\title{
Submandibular Tükürük Bezinde Dev Sialolit: Olgu Sunumu ve Literatür Derlemesi
}

\author{
A Giant Sialolith in Submandibular Gland: \\ A Case Report With Rewiew of Literature
}

ÖZ

Sialolitler tükürük bezlerinde bulunan kalsifiye organik yapılardır. Tükürük bezi taşları en sık submandibular bezde görülmekle birlikte, ikinci sıklıkla parotis bezinde görülürler. Sublingual bezlerde ve minor tükürük bezlerinde daha nadir izlenirler. Literatürdeki olguların çoğu, bez parankiminde oluşan tükürük bezi taşlarından oluşmaktadır ve sıklıkla 3-7 mm boyutunda izlenirler. Bu makalede submandibular bez hilumunda oluşan, 20x18 mm boyutundaki submandibular tükürük bezi taşı literatür derlemesi ile birlikte sunulmaktadır.

Anahtar sözcükler: Sialolit, Tükürük bezleri, Submandibular tükürük bezi.

\begin{abstract}
Sialoliths are calcified organic materials that forms in the salivary glands. Sialoliths are most commonly found in the submandibular gland, followed by the parotid gland. They are less common in the sublingual glands and minor salivary glands. Large sialoliths have been reported in the parenchyma of salivary glands and are often seen in 3-7 mm size. In this case report, 20x18 mm sialolith which is formed in hilum of submandibular salivary gland is presented together with the literature review.
\end{abstract}

Key words: Sialolith, Salivary glands, Submandibular gland.

\section{GíRIŞ}

Sialolitler tükürük bezlerinde bulunan kalsifiye yapılardır ve tükürük bezlerinin en sık görülen patolojileridir (1,2). Erkekler kadınlardan 2 kat daha fazla etkilenir $(3,4)$. Her yaşta görülebilmekle birlikte sıklıkla 4., 5 . ve 6. dekatlarda izlenir (5). Asemptomatik olabileceği gibi genellikle ağız tabanında ağrı ve şişliğe neden olurlar (6).

Tükürük bezi taşları en sık submandibular bezde (\%72-95) görülmekle birlikte, ikinci sıklıkla parotis bezinde (\%4-28) görülürler. Sublingual bezlerde ve minor tükürük bezlerinde daha nadir izlenirler $(7,8,9,10,11)$.

Tükürük bezi taşı oluşumuna kanalın anatomik yapısı, iltihabi durumlar, pH değişikliği ve hiposalivasyon zemin hazırlayabilir $(12,13,14)$. Taşın inorganik
Yeşim DENİZ ${ }^{1}$

Gediz GEDUK ${ }^{2}$

1 Samsun Ağız ve Diş Sağlığı Hastanesi, Ağı, Diş ve Çene Radyolojisi Birimi, Samsun, Türkiye

2 Bülent Ecevit Üniversitesi Diş Hekimliği Fakültesi, Ağız, Diş ve Çene Radyolojisi Anabilim Dalı, Zonguldak, Türkiye

Geliş tarihi / Received: 20.10.2017 Kabul tarihi / Accepted: 07.12.2017 DOI: $\operatorname{xxxxxxxxxxx}$

İletişim Adresi/Corresponding Adress: Yeşim DENİZ

Samsun Ağız ve Diş Sağlığı Hastanesi, Ağız, Diş ve Çene Radyolojisi Birimi, Samsun, Türkiye

E-posta/e-mail: yesim.deniz@saglik.gov.tr 
yapısını çoğunlukla kalsiyum fosfat ve kalsiyum karbonat kristalleri ve bunlarla birlikte magnezyum, potasyum ve bikarbonat gibi elementler oluşturur. Organik yapisinda ise karbonhidrat ve aminoasitler bulunur (15). Tükürük bezi hastalıklarının tanısında direkt radyografi, sialografi, ultrasonografi, sintigrafi, bilgisayarlı tomografi (BT), manyetik rezonans görüntüleme teknikleri kullanılabilir (16). Dental volumetrik tomografi (DVT) ile ultrasonun sialolitlerin saptanmasındaki etkinlikleri karşılaştırıldığında yaklaşık olarak aynı oranda teşhise katkıda bulundukları gözlemlenmiştir. DVT' nin ultrasona göre sensitivitesi daha fazla olmak ile birlikte radyasyon dozu göz önünde bulundurulduğunda görüntülemede en sık tercih edilen yöntem ultrasondur (6).

Literatürdeki olguların çoğu, bez parankiminde oluşan tükürük bezi taşlarından oluşmaktadır ve sıklıkla 3-7 mm boyutunda izlenirler, $15 \mathrm{~mm}$ 'yi geçen taşlara ise nadiren rastlanır $(17,18,19)$. Bu makalede wharton kanalının submandibular bezden çıkış bölgesi olan hilumda oluşan, 20x18 mm boyutundaki submandibular tükürük bezi taşı literatür derlemesi ile birlikte sunulmaktadır.

\section{OLGU SUNUMU}

Herhangi bir sistemik rahatsızlığ yaşında kadın hasta hareketli protezlerini yeniletmek amacıyla kliniğimize başvurdu. Ekstraoral muayenede, sol submandibular bölgede palpasyonda ağrısız, sert şişlik tespit edildi. Anamnezinde, yaklaşık 6 yıldır sol submandibular bölgede hafif şişlik olduğu ve özellikle yemek yerken hafif bir ağrı hissettiği ancak ağrının uzun sürmemesinden dolayı hastanın çok rahatsız olmadığı öğrenildi.

Alınan panoramik radyografta, sol submandibular tükürük bezi bölgesinde sirküler, radyopak, tabanı düzensiz yapıda ve 1,5x2 cm ebatlarında kitle görüldü (Şekil 1). USG görüntüsünde sağ submandibular bez $13 \times 26 \mathrm{~mm}$, sol submandibular bez $14 \times 25 \mathrm{~mm}$ boyutlarinda ve sol submandibular bez posterosüperiorunda yaklaşı 15x15 $\mathrm{mm}$ boyutunda, hiperekojen, düzgün sınırlı, kalsifik lezyon izlendi.

Sialolit veya lenf bezi kalsifikasyonundan şüphelenilip yumuşak doku ile kitle ilişkisini daha net ayırt etmek amacıyla Bilgisayarlı Tomografi (BT) tetkiki istendi. Maksillofasiyal BT incelemesinde sol submandibular bez medial süperiorunda yaklaşık 20x18 mm boyutunda, düzgün sınırlı, kemik korteks dansitesinde nodüler lezyon izlendi (Şekil 2,3,4). Klinik, radyografik ve ultrasonik tetkikler ışığında kitleye submandibular sialolit tanısı konuldu ve hasta bilgilendirildi. Sialolitin büyük olması sebebiyle ve yaratabileceği rahatsızlıklardan dolayı cerrahi olarak alınması planlandı ancak hasta isteğiyle takip kararı alındı.

\section{TARTIŞMA}

Sialolitler tükürük bezi içerisinde ve kanal yapısında oluşan kalsifiye yapılar olarak tanımlanmaktadır. Sialolitler, erișkinlerde tükürük bezlerinde görülen en yaygın patolojilerdendir ve herhangi bir tükürük bezinde oluşabilir. Escudier ve Mc Gurk çalışmalarında siololitlerin görülme oranını 15000 - 30000 hastada bir olarak, Taher ise 1000 hastanın 7.3 ünde sialolit bulunduğunu rapor etmişlerdir $(20,21)$.

Taher 1000 hasta üzerinde yaptığg çalışmasında hastaların $\% 0,73$ 'ünde sialolit gözlemlemiştir ve bu hastaların \%75.86'sının erkek hasta olduğunu rapor etmiștir (21). Laforgia ve ark. 400 sialolit olgusunda yaptıkları incelemede hastaların \%70'inin erkek hasta olduğunu ve sialolitlerin 2. ve 4. dekatlar arasında daha sık izlendiğini tespit etmiştir (22). Schrøder ve ark. ise cinsiyetler arasında farklılık gözlemlememişlerdir. Tükürük bezi taşı bulunan hastaların ortalama yaşını $48.2 \pm 18.3$ olarak tespit eden araştırmacılar, erkeklerin ortalama yaşını $46.9 \pm 17.3$, kadınların ortalama yaşını ise $49.6 \pm 17.6$ olarak tespit etmişlerdir. Tükürük bezi taşı bulunan hastaların \%75’i 36-61 yaşları arasındadır (23). Bizim olgumuz ise 60 yaşında kadın hastada submandibular tükürük bezi taşı görülmüştür.

Sialolitlerin etiyolojisi hâlâ netlik kazanmamıştır. Fakat Zenk ve ark. (24), ve Huoh ve ark. (25), böbrek taşı bulunan hastaların çoğunda tükürük bezi taşı da bulunduğunu bildirmişlerdir. Laforgia ve ark. diabetli hastaların \%25' inde, hipertansiyonlu hastaların ise \%20' sinde tükürük bezi taşı olduğunu gözlemlemişlerdir (26). Metildopa, levodopa ve amantadin gibi bazı ilaçlar nedeniyle tükürük bezlerinde taş oluştuğunu savunan yazarlar da bulunmaktadır $(27,28)$. Diğer bir hipotez ise Sjögren sendromunda azalan tükürük akışı ile tükürük bezi taşı oluşumunun arttığı yönündedir (29). Kaarij ve ark., yaptıkları çalışmada sistemik hastalıklarla ve kullanılan ilaçlarla sialolit prevalansı arasında bir ilişki bulamamışlardır. Antibiyotik kullanan hastalarda daha fazla sialolite rastlayan araştırmacılar sialolithiazis nedeniyle ilk tedavinin antibiyotik tedavisi ile yapıldığını, bu sebeple antibiyotiklerin tükrük bezi taşı oluşumunu etkilemediğini savunmuşlardır (30). Laforgia ve ark. 400 sialolit olgusunun $\% 25$ 'inde diabet hastalığ 
bulunduğunu, \%20'sinde hipertansiyon ve \%10'unda karaciğer rahatsızlığı bulunduğunu rapor etmişlerdir (22).

Sialolit, en s1k submandibular tükürük bezinde görülmesinin yanında tükürük bezlerinde en sık görülen patolojidir $(1,31,32,33)$. Lustman ve ark, çalışmalarında sialolit bulunan 245 hastanın 231 tanesinin submandi-

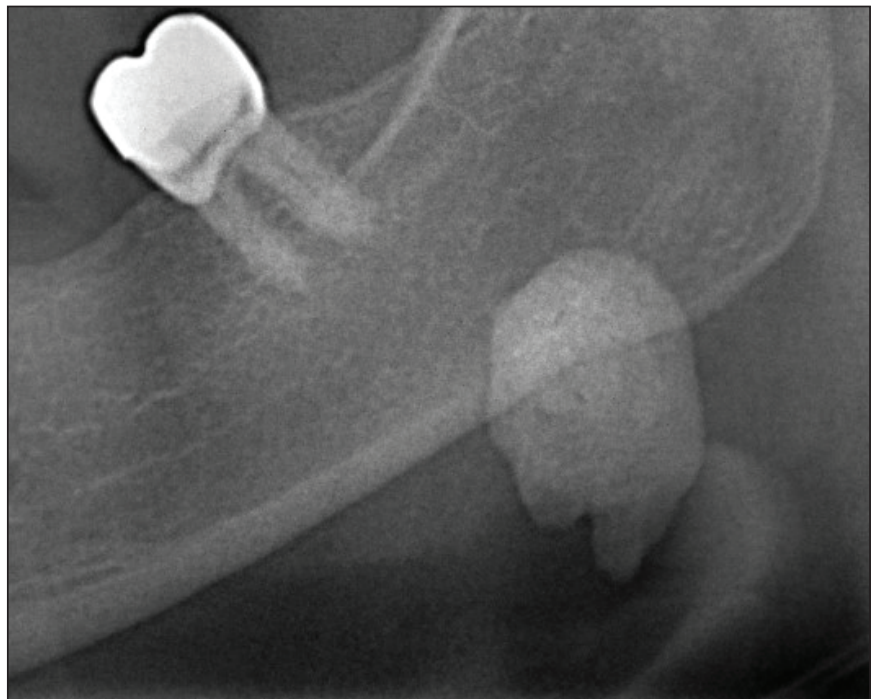

Şekil 1: Panoramik radyografta sol submandibular tükürük bezi bölgesinde sirküler ve $1,5 \times 2 \mathrm{~cm}$ ebatlarında radyoopak kitle görülmektedir.

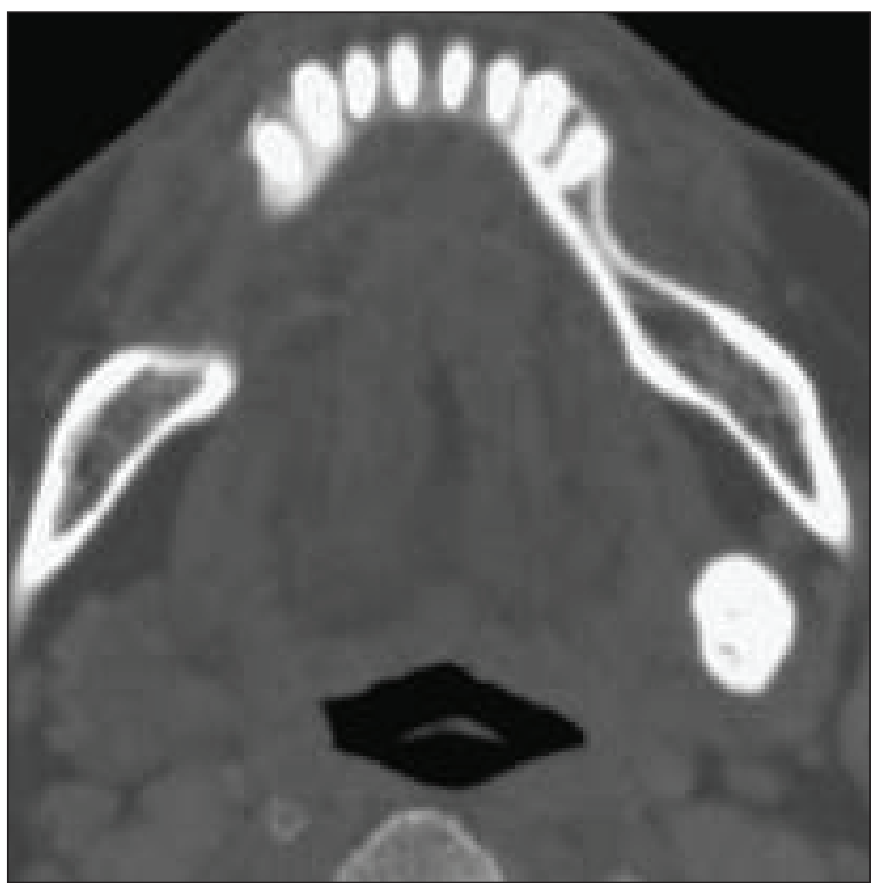

Şekil 2: BT incelemesinde sol submandibular bez medial süperiorunda yaklaşık 18x20 mm boyutunda, düzgün sınırlı, kemik korteks dansitesinde nodüler lezyon izlendi. bular bezinde, 11 tanesinin parotis bezinde ve 1 hastanın sublingual bezinde sialolit gözlemlemişlerdir. Diğer tükürük bezlerine göre submandibular bezde sialolitlerin daha fazla görülmesi wharton kanalının anatomik yapısından ve sekresyonun içeriğinden kaynaklanmaktadır. Wharton kanalının daha uzun, geniş, kıvrımlı yapıda olması ve kanal ağzının küçük olması sekresyo-

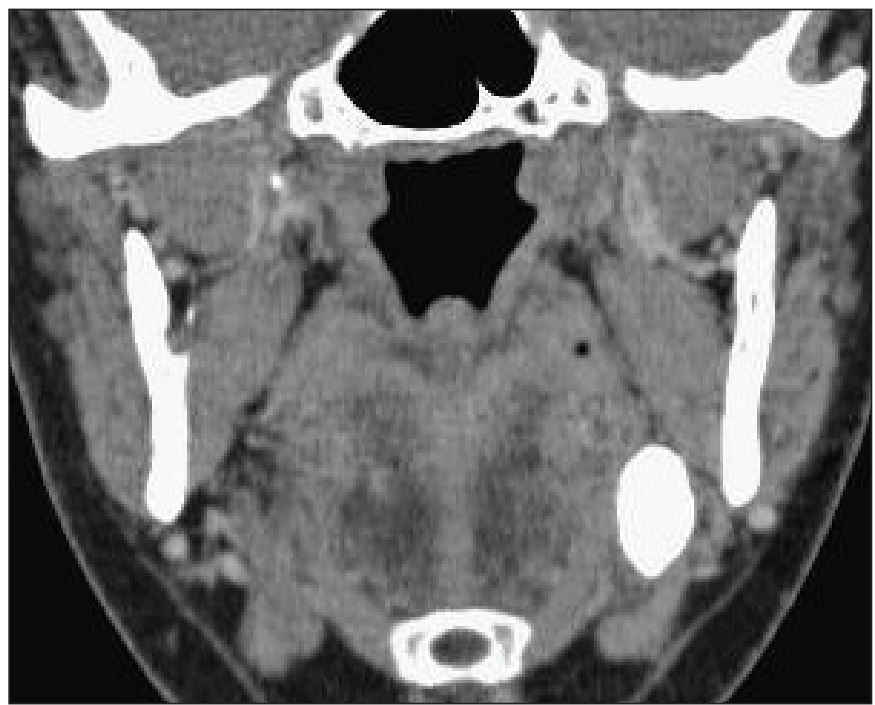

Şekil 3: BT koronal kesit incelemesinde kemik korteksi densitesindeki lezyonun görünümü.

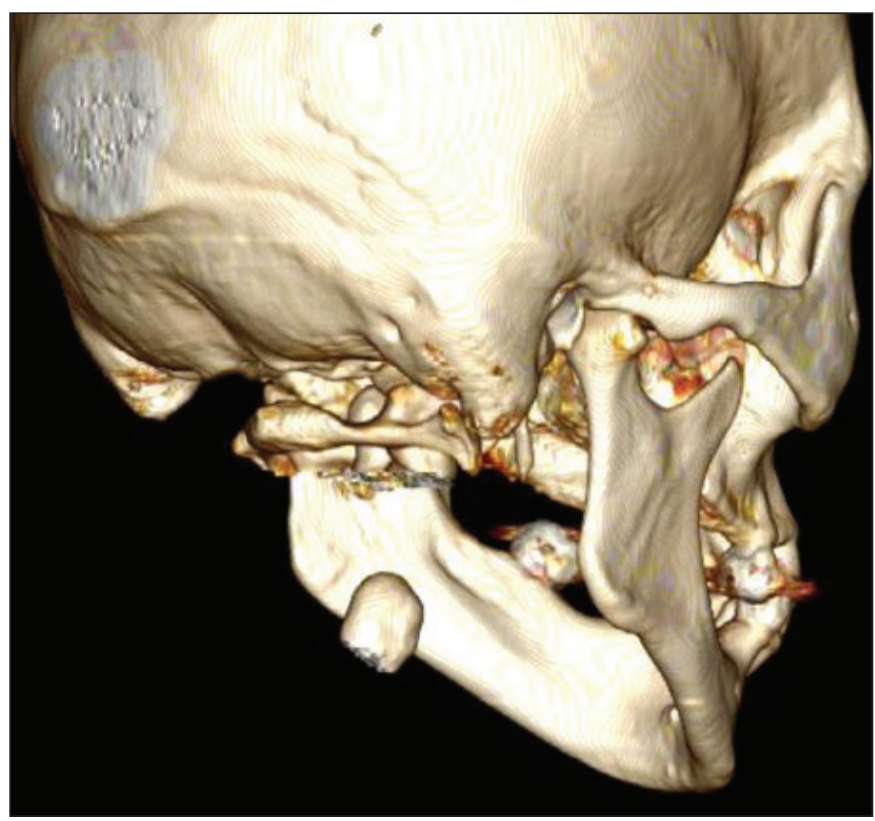

Şekil 4: BT görüntüleme, volumetrik rekonstrüksiyon incelemesinde düzgün sinırlı yapıda sol submandibular bez posteriorunda nodüler lezyonun görünümü. 
nunun akıșını yavaşlatır. Sekresyonun yerçekimine zıt yönde akması, içeriğinin daha alkali olması ve musinden, proteinlerden, kalsiyum ve fosfattan zengin olması sialolitlerin oluşmasına zemin hazırlayan faktörlerdir $(1,18,31,32,34,35,36)$.

Çoğu submandibular sialolit, bezin kanal sisteminde bulunur (\%75-85); hilum bölgesi ve tükürük bezi parankimi içinde ise nadir olarak görülmektedir (33). $\mathrm{Bu}$ olguda görülen sialolit nadir olarak görülen hilum bölgesinde oluşmuștur. Kanal sistemi içerisinde bulunan büyük boyutlardaki sialolitler, uzamış ve silindirik şekilde görülebilirken hilum bölgesinde bulunanlar sirküler şekilde izlenebilmektedir $(18,19)$.

Sialolitlerde şikayetin derecesi olgudan olguya değişiklik gösterebilmektedir. Sialolitler asemptomatik olabileceği gibi genellikle ağız tabanında ağrı ve şişlik hikayesi ile birlikte görülebilir. Parotis bezinde oluşan sialolitler çoğunlukla yanakta şişliğe neden olur. Hastalarda yemek yeme ile ve tükürük akışının stimüle edildiği durumlarda şiddetliveya hafifağrıloluşabilir. Tükürükbezinitamamen tıkamayan sialolitlerin varlığında ağrı ve şişlik yavaşça azalma eğilimindedir (1). Şikayet minimal seyretmiş ve hasta özellikle yemek yediği zamanlarda hafif rahatsızlık hissetmiştir. Bu geçici ağrının sebebinin sialolitin, wharton kanalını tam olarak tıkamaması ve kanalın bir kısmından tükürük akışının sağlanması olduğu düşünülmektedir. Ağız kuruluğu (37), ağız tabanında farkedilebilir şişlik (32), submandibular bölgede şiddetli ağrı ve ağız açmada kısıtlılığa bağlı konuşmada güçlüğe sebep olan (38), olgular da bildirilmiştir.

Sialolitlerin kompozisyonu çeşitlilik gösterebilir ancak siklıkla kalsiyum ve fosfat tuzlarının yanında hidroksiapatit, amorf kalsiyum fosfat, karboksi apatit ve müsin gibi fibröz proteinlerle birlikte whitlokit de bulunmaktadır $(1,39)$. Taher çalışmasında tükürük bezi taşlarının ortalama olarak \%89.77'sini fosfat tuzları, \%7.98'ini oksalat tuzları, \%2.27'sini urate tuzlarının oluşturduğunu tespit etmiştir (21).

Büyük sialolitlerin teşhisinde düz grafiler yeterli olurken, küçük, kısmi kalsifiye ve radyolüsent taşlar düz grafilerle seçilemeyebilir. Sialolitleri düz grafilerde görüntüleyebilmek için ekspoz süresinin yarıa düşürülmesi önerilir. Düz grafilerde teşhis edilemeyen küçük sialolitler için bilgisayarlı tomografi (BT) kullanılabilir. BT tükürük beziyle birlikte tükürük bezi kanalını görüntülemede de faydalı olmaktadır (39). Radyolüsent tükürük bezi taşlarını saptamada ise sialografi ve ultrason kullanilabilir. Sialografide kontrast maddeler genellikle sialolitin etrafinda akar, kanaldaki obstrüksiyonun proksimalini doldurur (1). Wharton kanalının distal kısmındaki taşlar için ise en iyi görüntüleme yöntemi normal ekspoz süresini yarıya düşürerek alınan mandibular okluzal grafilerdir (1). Daha posteriorda yerleşen taşlar ise en iyi lateral oblik grafi veya panoramik radyografi ile görüntülenir. Diş hekimliğinde kullanımı gittikçe artan dental volumetrik tomografi (DVT) de küçük boyutlu ve gözden kaçan sialolitlerin tespit edilmesine olanak sağlamaktadır. Ancak sialolitlerin görüntülenmesinde kullanılabilecek en iyi yöntemler sialografi ve ultrasondur. Ultrason, minimal invaziv yaklaşım sağlaması, tükürük bezi parankimini, kanal sistemini net olarak göstermesi ve kısa sürede sonuç vermesinden dolayı sialolit görüntülemesinde altın standart olarak kabul görmektedir (40).

Radyolojik incelemede, tükürük bezi taşları genellikle silindirden, oval ve yuvarlak şekile kadar değişiklik gösteren, homojen radyoopak yapılar olarak görülürler. Kalsifikasyon derecesine bağlı olarak homojen radyopak izlenebildiği gibi radyolüsent görüntü de verebilirler. Olguların \%20-\%40'ı radyoopak görünecek kadar kalsifiye olmazlar ve 'mükoz tıkaçlar' olarak isimlendirilirler (1). Submandibular sialolitlerin \%20'si ve parotiste görülen sialolitlerin $\% 40$ '1 radyolüsenttir. Parotisteki sialolitlerin submandibular sialolitlere göre daha fazla oranda radyolüsent görünmesinin sebebi, parotis bezinden salgılanan sekresyonun düşük mineral içeriğidir (1). Radyoopak taşlar genellikle periapikal ve panoramik görüntülerde, mandibular premolar ve molar dişlerin kökleri üzerine süperpoze olurlar.

Sialolitler, flebolitlerden ve lenf bezlerinin distrofik kalsifikasyonlarından ayırt edilmelidir. Flebolitler genellikle radyolüsent bir merkeze sahiptirler. Kalsifiye lenf nodları ise genellikle 'karnıbahar' görünümünde izlenirler. Panoramik grafilerde, palatin tonsilitler ramusun üzerinde süperpoze olarak parotis sialolitlerine benzer lokalizasyonda izlenirler; fakat tipik olarak multiple, benekli görünümleriyle ve oklüzal düzlemin altında görülmeleriyle ayırt edilebilirler $(1,40)$.

Sialolitler sekretuar kanalları tıkayabilirler; böylelikle tükürük akışını azaltarak kronik retrograd enfeksiyonlara neden olabilirler. Sialo-oral fistül $(41,42,43)$, sialokutanöz fistül (44), bezin atrofisine ve fibrozisine $(45,46)$ yol açabileceği için çıkarılmalıdır. Tehar, çalışmasında sialolit ihtiva eden tükürük bezlerinin \%91.57'ünde enfeksiyon geliştiğini rapor etmiştir (21).

Küçük taşlar genelde bimanuel palpasyonla sağma yöntemiyle ve sialogog ajanların kullanılmasıyla dışarı çıkarılabilir (1,39). Bununla birlikte çıkarılamayan 
küçük, asemptomatik taşlar takip edilebilir (47). Ciddi büyüklükte veya intraparankimal sialolitler cerrahi olarak taşın veya tamamen bezin çıkarılmasıyla tedavi edilebilir (48-51). Bunun yanında literatürde minimal invaziv bir yöntem olan piezoelektrik cerrahi ile parçalanarak çıkarılan sialolitler de rapor edilmiştir (52).

Hastanın tükürük bezi taşıyla ilgili tedavi görmek istememesinden ve öncelikli diş eksikliğinin giderilmesini istemesinden dolayı planlanan cerrahi tedavi yapılmamıștır. Hastaya şikayetlerinin artması durumunda başvurması ve kontrol amaçlı düzenli takip randevularına gelmesi söylenmiştir.

\section{KAYNAKLAR}

1. White SC ve Pharoah MJ. Oral Radiology Principles and Interpretation. 7th Ed., St. Louis, Mosby Elsevier. 2014.

2. Rauch S, Gorlin RJ. Diseases of the salivary glands. In: Gorlin RJ, Goldman HM, editors. Thoma's Oral Pathology. St. Louis: Mosby, 1970.

3. Rai M, Burman R. Giant submandibular sialolith of remarkable size in the comma area of Wharton's duct: A case report. J Oral Maxillofac Surg 2009;67:1329-32.

4. Paul D, Chauhan SR. Salivary megalith with a sialocutaneous and a sialo-oral fistula: A case report. J Laryngol Otol 1995;109:767-9.

5. Lustmann J, Regev E, Melamed Y. Sialolithiasis. A survey on 245 patients and a review of the literature. Int J Oral Maxillofac Surg 1990;19:135-8.

6. Schwarz D, Kabbasch C, Scheer M, Mikolajczak S, Beutner D, Luers JC. Comparative analysis of sialendoscopy, sonography, and CBCT in the detection of sialolithiasis. Laryngoscope. 2015 May;125(5):1098-101.

7. Levy DM, Remine WH, Devine KD. Salivary gland calculi. Pain, swelling associated with eating. J Am Med Assoc. 1962;181: 1115-1119.

8. Lustmann J, Regev E, Melamed Y. Sialolithiasisda survey on 245 patients and a review of the literature. Int J Oral Maxillofac Surg. 1990;19:135-138.

9. Mark F, Williams M. Sialolithiasis. Otolaryngol Clin N Am. 1999;32:819-833.

10. Zenk J, Constantinidis J, Kydles S, Hornung J, Iro H. Klinische und diagnostische Befunde bei der Sialolithiasis. HNO. 1999;47: 963-969.

11. Kraaij S, Karagozoglu KH, Forouzanfar T, Veerman ECI, Brand HS. Salivary stones: symptoms, aetiology, biochemical composition and treatment. $\mathrm{Br}$ Dent J. 2014;217:E23.
12. Ord RA. Salivary Gland Disease. In: Fonseca RJ, edit. Oral and Maksillofacial Surgery. Vol. 5, Philadelphia, London, New York, St. Louis, Toronto. W.B. Saunders Company 2000; 273-93.

13. Paterson JR, Murphy MJ. Bones, groans, moans... and salivary stones? J Clin Pathol. 2001;54:412.

14. Andretta M, Tregnaghi A,Prosenikliev, Staffieri A. Current opinions in sialolithiasis diagnosis and treatment. Acta Otorhinolaryngol Ital. 2005; 25:145-9.

15. Hiraide F, Nomura Y. The fine surface structure and composition of salivary calculi. Laryngoscope 1980;90: 152-8.

16. Çağlayan F, Çakur B, Harorlı A. Tükürük bezlerinin radyografik muayene yöntemleri ve sialografi. Atatürk Üniv Diş Hek Fak Derg 2003 :13(2); 99-111.

17. Fowell $\mathrm{C}$ ve MacBean A. Giant salivary calculi of the submandibular gland. J Surg Case Rep, 2012. 2012(9): p. 6.

18. Banerjee K, et al. Surgical removal of a submandibular megalith. BMJ Case Rep, 2013. 2013.

19. Hazarika P., et al., Deep and unusual sialolithiasis of submandibular duct and gland: a surgical dilemma. Indian J Otolaryngol Head Neck Surg, 2013. 65(4): p. 309-13.

20. Escudier MP, McGurk M. Symptomatic sialoadenitis and sialolithiasis in the English population, an estimate of the cost of hospital treatment. Br Dent J 1999;186:463-466.

21. Taher AA. The incidence and composition of salivary stones (sialolithiasis) in Iran: analysis of 95 cases. Singapore Dent J. 1989;14:33-35.

22. Laforgia PD, Favia GF, Chiaravalle N, Lacaita MG, Laforgia A. Clinico-statistical, morphologic and microstructural analysis of 400 cases of sialolithiasis. Minerva Stomatol. 1989;38: 1329-1336.

23. Schrøder S, Homøe P, Wagner N, Vataire AL, Lundager Madsen HE, Bardow A. Does drinking water influence hospital-admitted sialolithiasis on an epidemiological level in Denmark? BMJ Open. 2015 May 3;5(4):e007385.

24. Zenk J, Constantinidis J, Kydles S, Hornung J, Iro H. Klinische und diagnostische Befunde bei der Sialolithiasis HNO, 47 (1999), pp. 963-969.

25. Huoh KC, Eisele DW. Etiologic factors in sialolithiasis. Otolaryngol Head Neck Surg, 145 (2011), pp. 935-939.

26. Laforgia PD, Favia GF, Chiaravalle N, Lacaita MG, Laforgia A. Clinico-statistical, morphologic and microstructural analysis of 400 cases of sialolithiasis. Minerva Stomatol, 38 (1989), pp. 1329-133.

27. R.J. Perrotta, J.R. Williams, R.W. Selfe. Simultaneous bilateral parotid and submandibular gland calculi. Arch Otolaryngol Head Neck Surg, 104 (1978), pp. 469-470.

28. C. Lutcavage, S. Schaberg. Bilateral submandibular sialolithiasis and concurrent sialadenitis. J Oral Maxillofac Surg, 49 (1991), pp. 1220-1222. 
29. G.B. Proctor, S.M. Osailan, M. McGurk, J.D. Harrison. Sialolithiasis-pathophysiology, epidemiology and aetiology .O. Nahlilie, H. Iro, M. McGurk, J. Zenk (Eds.), Modern Management of Preserving the Salivary Glands, Herseliya, Isradon, Israel (2007), pp. 91-142.

30. Kraaij S, Karagozoglu KH, Kenter YA, Pijpe J, Gilijamse $\mathrm{M}$, Brand HS. Systemic diseases and the risk of developing salivary stones: a case control study. OralSurg Oral Med Oral Pathol Oral Radiol. 2015 May;119(5):539-43.

31. Jardim, E.C., et al., Sialolithiasis of the submandibular gland. J Craniofac Surg, 2011. 22(3): p. 1128-31.

32. Ben-Shoshan, M. and Y. Lacroix, A giant sialolith in a 16-year-old boy presenting to the emergency room. Arch Dis Child, 2014. 99(9): p. 883.

33. Sunder, V.S., et al., Multiple bilateral submandibular gland sialolithiasis. Niger J Clin Pract, 2014. 17(1): p. 115-8.

34. Ledesma-Montes C, Garcés-Ortíz M, Salcido-García JF, Hernández- Flores F, Hernández-Guerrero JC. Giant sialolith: Case report and review of the literature. J Oral Maxillofac Surg 2007;65:128-30.

35. Chan EK, Patel ND. Giant calculus of the submandibular salivary duct. Ear Nose Throat J 2006;85:306, 308.

36. Abdeen BE, Khen MA. An unusual large submandibular gland calculus: A case report. Smile Dent J 2010;5:14-7. 37.

37. Jung, J.H., et al., A large sialolith on the parenchyma of the submandibular gland: A case report. Exp Ther Med, 2014. 8(2): p. 525-526.

38. Franco, A., et al., Massive Submandibular Sialolith: Complete Radiographic Registration and Biochemical Analysis through X-Ray Diffraction. Case Rep Surg, 2014. 2014: p. 659270.

39. Delli, K., F.K. Spijkervet, and A. Vissink, Salivary gland diseases: infections, sialolithiasis and mucoceles. Monogr Oral Sci, 2014. 24: p. 135-48.

40. Caglayan, F., et al., Are all soft tissue calcifications detected by cone-beam computed tomography in the submandibular region sialoliths? J Oral Maxillofac Surg, 2014. 72(8): p. 1531.e1-6.
41. Hubar JS, Guggenheimer J, Evan M. Megalith. Oral Surg Oral Med Oral Pathol 1990;70:245.

42. Akimoto Y, Sakae T, Toyoda C, Ono M, Hasegawa K, Tanaka S, et al. An unusually large submandibular salivary calculus: Case report and structural analysis. Int J Oral Med Sci 2004;2:50-3.

43. Patil S, Sharma S, Prasad LK. Submandibular megalith with erosion of the floor of mouth - A rare case report. World Article in Ear Nose and Throat 2009;2.

44. Paul D, Chauhan SR. Salivary megalith with a sialocutaneous and a sialo-oral fistula: A case report. J Laryngol Otol 1995;109:767-9. Siddiqui SJ. Sialolithiasis: An unusually large submandibular salivary stone. Br Dent J 2002;193:89-91.

45. SiddiquiSJ. Sialolithiasis: An unusuallylarge submandibular salivary stone. Br Dent J 2002;193:89-91.

46. García-Consuegra L, Rosado P, Gallego L, Junquera L. Unilateral absence of submandibular gland secondary to stones. Aplasia versus early atrophy. Med Oral Patol Oral Cir Bucal 2010;15:e752-4.

47. Miloğlu Ö, Çağlayan F, Ezmeci T, Dağıstan S, Demirtaş DÖ. Multiple cases of submandibular sialolithiasis detected by cone beam computed tomography. Atatürk Üniv Diş Hek Fak Derg 2010;20(3):189-193.

48. Austin, T., J. Davis, and T. Chan, Sialolithiasis of submandibular gland. J Emerg Med, 2004. 26(2): p. 221-3.

49. Iqbal, A., et al., Unusually large sialolith of Wharton's duct. Ann Maxillofac Surg, 2012. 2(1): p. 70-3.

50. Parkar, M.I., M.M. Vora, and D.H. Bhanushali, A Large Sialolith Perforating the Wharton's Duct: Review of Literature and a Case Report. J Maxillofac Oral Surg, 2012. 11(4): p. 477-82.

51. Yaman F, Gülten Ü, Atilgan S. Ağiz İçine Sürmüş Submandibular Sialolitiazis:(Olgu Sunumu). Atatürk Üniv Diş Hek Fak Derg 2006;16(2):70-73.

52. Pastor-Ramos, V., A. Cuervo-Diaz, and L. Aracil-Kessler, Sialolithiasis. Proposal for a new minimally invasive procedure: Piezoelectric surgery. J Clin Exp Dent, 2014. 6(3): p. e295-8. 